\title{
Tools for the Control of Modern Solar-Thermal Heating Plants *
}

\author{
Alice F. Branco* Marcelo M. Morato* G. A. Andrade* \\ Julio E. Normey-Rico* \\ * Grupo de Pesquisa em Energias Renováveis (GPER), Departamento \\ de Automação e Sistemas (DAS), Universidade Federal de Santa \\ Catarina (UFSC). (aliceferreirabranco@gmail.com, \\ marcelomnzm@gmail.com,gustavo.artur@ufsc.br, \\ julio.normey@ufsc.br)
}

\begin{abstract}
Among renewable sources, hopes are placed upon solar energy as a viable alternative for sustainable development. Apart from being clean, this source must be profitable and affordable, which can be achieved only if adequate tools are available, in such way that their dynamics can be predicted/analyzed and benefits are maximized. Thus, this short work proposes design tools for modern solar-thermal plants. Firstly, a phenomenological model is drawn, whose parameters are adjusted for a real testbed. Then, considering real data, three different identification procedures are performed (ranging from nonlinear least-squares to frequencywise methods). Also, in the aims of feedforward compensation applications, an estimation layer is proposed, based on Neural Networks, to predict solar irrandiance disturbances. Simulation results assess that the models are useful for control purposes.

Resumo: Entre as fontes renováveis, há expectativas para energia solar ser uma alternativa viável para o desenvolvimento sustentável. Além de ser limpa, esta fonte deve ser rentável e acessível, algo que somente pode ser atingido se determinadas ferramentas estiverem disponíveis, de maneira que as dinâmicas do processo possam ser preditas/analisadas e os benefícios maximizados. Dessa maneira, este trabalho propõe ferramentas de projeto para plantas solar térmicas modernas. Primeiramente, um modelo fenomenológico é traçado, para os quais os parâmetros são ajustados a uma planta real. Então, considerando dados reais, três procedimentos de identificação diferentes são realizados (mínimos quadrados não-linear até métodos baseados na frequência). Visando aplicações de compensação feedforward, também foi proposta uma camada de estimação de Redes Neurais, para prever as perturbações causadas pela irradiação solar. Os modelos são comparados via simulação e provam-se úteis para intenções de controle.
\end{abstract}

Keywords: Solar Energy; Least-Squares; Neural Networks; Model Validation.

Palavras-chaves: Energia Solar; Mínimos-Quadrados; Redes Neurais; Validação de Modelo.

\section{INTRODUCTION}

The use and generation of energy in efficient ways are key elements for achieving more ambitious goals sustainability goals. The current foundations on energy generation are about to change in a profound way Johansson (1993): the prices of fossil fuels are rising each year Shafiee and Topal (2010) whereas, at the same time, energy demands grow in every country and the search for viable renewable sources becomes evermore important Shafiee and Topal (2009).

Recent academic research has given focus to generalized energy systems, with multiple generation and different energy carriers. The growing scope of research in this topic can be illustrated by some references, see the large review of the state-of-the-art on multi-objective planning of these distributed plants, Alarcon-Rodriguez et al. (2010) and references therein.

* The authors thank $C N P q$ for financing projects 401126/2014-5 303702/2011-7 and 305785/2015-0.
Much is discussed on the use of renewables, but it is important to remark that, although these seem very appealing, they are intermittent, difficult to predict, heavily dependent on the weather conditions upon the energy plant and dealing with them is a defying factor for system safety and technical-economical network management.

The integration of renewable sources to power systems can be a good alternative to avoid greenhouse emissions and environmental impact, but a problem to be solved is how to integrate these energy sources without loosing efficiency and dispatchability of energy plants. In sum, the biggest affair related with this kind of system is the unreliability and inconstant quality of the renewable energy sources, these being intermittent and inducing unpredictable fluctuations on the energy output. A practical solution to this matter is to include intermediate energy storage banks, such as batteries, heated water tanks, super-capacitors, fly wheels and others Dell and Rand (2001). 
The prediction of the behavior of these renewable sources can elevate internal system stability, safety and also enable better management of energy demand. If a controller knew the complete future information of these disturbances, a feedforward compensation $(F F)$ could be formulated so that energy production output would be immune to their variations. Given this context, an accurate prediction of disturbance curves can enhance a controlled system's performance, with the use of $F F$ action. Considering this kind of application, it should be mentioned that solar irradiance has a stochastic behavior that represents an additional challenge to energy management in renewable energy based power systems. Thus, the estimation of the future behavior of these variables is of great importance.

\subsection{Problem Statement}

The Control Systems community has praised some recent works considering energy management for microgrids with stochastic disturbances. This is seen various recent works Yu et al. (2013); Vergara-Dietrich et al. (2017). But, to do so, two things are fundamental:

(1) An accurate model of the controlled system or microgrid (this could be an Energy Hub-based model from a supervisory level, as done in Morato et al. (2018) or a close-to-plant realistic model of the renewable system);

(2) An efficient prediction layer for the renewable disturbance.

Notably, in the instance of this work, the issue of solar power will be taken into account. Bearing in mind the current energy transition context and given what has been pointed out about control and management of renewable microgrids, this work aims to:

(i) Propose an adequate phenomenological model for modern Solar-Thermal $(S T)$ heating facilities, which is validated considering real test-bench (Section 3);

(ii) To have parallel comparison, propose data-drive identification-derived models for these $S T$ units (Section 4);

(iii) Propose a disturbance estimation layer with longterm prediction horizons for solar irradiance, as discussed by Reikard (2009), that can provide future disturbance predictions in different time scales (Section $5)$.

With these tools (good model plus irradiance estimator, see Figure 1), some (optimal) control application could be effectively implemented in future works, using, for instance, Model Predictive Control, as successfully done in Morato et al. (2017b).

This paper has its preliminaries recalled in Section 2, detailing the studied solar-thermal heating process and the available data; Section 6 shows the achieved results, comparing models with real data; the work ends with Conclusions.

\section{NOTATION AND PRELIMINARIES}

As discussed Camacho et al. (2012), current solar energy technologies are of two main kinds: either photovoltaic $(P V)$ systems, that directly covert solar irradiance into

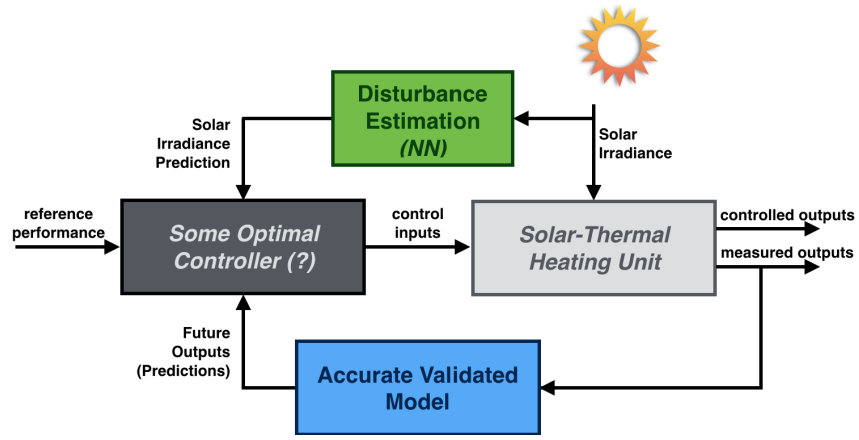

Figure 1. ST Heating Unit: Tools

electric energy, and solar-thermal $(S T)$ systems, which usually generate heat. In terms of the latter branch, it has to be remarked that low-temperature $S T$ schemes are widely used in the industry, with various applications, as those in Leblanc et al. (2010); Bujedo et al. (2011); Marc et al. (2012) and Rosiek and Batlles (2009).

As discussed, solar irradiance is an intermittent energy source. When there occurs a cloudy period of the day, for instance, energy might be running low if no compensation strategy is considered. As proposed by Dell and Rand (2001), a practical solution for this matter, considering $S T$ systems, is to include accumulation tanks to store energy while there is no process demand, and a complementary (auxiliar) energy source (say, for instance, a gas heater), that could be of use when there is no sun or (and) the accumulation tanks are not sufficient to meet the demand fully.

Henceforth, a modern $S T$ system can be understood as a structure that integrates a solar-thermal collector field, some accumulation tanks and a gas heater. Of course, each subsystem has independent dynamics that influence strongly the total output dynamics; so, to analyse the global behaviour of a modern $S T$ scheme is a complex task. The main task herein is, thence, to propose some models (both phenomenological and identification-based) that can describe the global (input-output) dynamics of these adapted $S T$ plants.

\subsection{Validation Test-bench}

In this work, one of these modern $S T$ systems is used as a test-bed for model-validation purposes. This plant is located in the CIESOL-ARFR-ISOL R\&D Centre of the University of Almería, Spain (research partner of the authors). This test-bench plant has also been used in Pasamontes et al. (2013): more details are given therein. This plant is considered to have all its subsystems in constant running operation mode. These three subsystems are:

(1) A ST flat collector field: used to increase the temperature of the inlet fluid to cover a certain heat demand. This collector field has $160 \mathrm{~m}^{2}$ of area, distributed in ten parallel rows with eight collectors per row. The temperature of these panels must not exceed $110^{\circ} \mathrm{C}$ to avoid damage.

(2) Two accumulation water tanks of $5 \mathrm{~m}^{3}$ each, connected in series. They are used to stored energy when there is no available solar source, or to smooth the 
effect of their abrupt variations. Both have a maximal storage capacity of $2020 \mathrm{~kJ}$.

(3) One gas heater: a Duplex Evo model, manufactured by ADISA Calefacción, with a nominal power of $116 \mathrm{~kW}$. In terms of restrictions, the use of this source is a constraint (in the view of control applications), being costly; its use is to be avoided.

\section{PHENOMENOLOGICAL DYNAMIC MODEL}

This Section describes the phenomenological model used to describe the dynamics of the studied modern $S T$ system. The following development is adapted from Pasamontes et al. (2013). The complete model is a combination of the phenomenological behaviours of the three subsystems.

\subsection{Water Tanks}

The accumulation tanks phenomenological model can be derived from the model presented in Cruickshank and Harrison (2006), that considers $m$ tanks connected in series, with $n_{m}$ segments per tank. Each $i$-th tank has the $j$-th segment volume $V_{t, i, j}$. The water inlet temperature is given by $T_{f_{i, j}}$. The thermal loss at each tank segment is given by $U_{a_{i, j}}$, per surface unit. The global heat transfer coefficient per surface unit between consecutive segments of tank $i$ is given by $U_{i, j, j+1}$. The internal area of the two segments in contact is given by $A_{i, j, k}$; the segment surface area is $A_{i, j}^{s}$. This leads to the dynamics presented below ${ }^{1}$, whose parameters are given in Pasamontes et al. (2013):

$$
\begin{gathered}
\rho_{f} C_{f} V_{i, j} \frac{\partial T_{i, j}}{\partial t}(t)=\rho_{f} C_{f} A_{i, j} v_{t}(t) T_{f_{i, j}}(t)+ \\
U_{a_{i, j}} A_{i, j}^{s}\left(T_{a}(t)-T_{i, j}(t)\right)+ \\
U_{i, j-1} A_{i, j-1, j}\left(T_{i, j-1}(t)-T_{i, j}(t)\right)+ \\
U_{i, j, j+1} A_{i, j, j+1}\left(T_{i, j+1}(t)-T_{i, j}(t)\right) .
\end{gathered}
$$

\subsection{Gas Heater}

The CIESOL testbed's gas heater's phenomenological model derives from heat exchange laws, similar to the ones in (1). This model has also been validated, with parameters identified in Pasamontes et al. (2013).

$$
\begin{aligned}
\rho_{f} C_{f} V_{g} \frac{d T_{g}}{d t}(t) & =U_{g} A_{e}\left(T_{e}(t)-T_{g}(t)\right) \\
& +R(t) U_{g c}\left(T_{g, g a s}(t)-T_{g}(t)\right) \\
& +C_{f} \rho_{f} \dot{q}_{g}(t)\left(T_{g, i n}(t)-T_{g}(t)\right),
\end{aligned}
$$

where $V_{g}$ is the volume of heated gas; $U_{g}$ and $U_{g c}$ are thermal loss coefficients; $T_{g, i n}$ and $T_{g}$ are the heater's inlet/outlet temperature, respectively; $T_{e}$ and $T_{g, \text { gas }}$ are, respectively, external temperature and the gas combustion temperature; $A_{e}$ is the gas conduct's external surface and, finally, $R$ is the gas heater regulator signal (disturbance) that defines the heater's power, from 0 to $100 \%$.

\footnotetext{
1 Where $C_{f}$ and $\rho_{f}$ stand for parametrical properties (heat capacity and density, respectively) of the fluid (water).
}

\subsection{Collector Field}

The flat solar collector panel model is presented in the sequence. Notice that the collector outlet flow depends on the following main factors: inlet water flow and temperature and amount of solar irradiance. Two coupled equations describe this behaviour, as proposed in Camacho et al. (2012) and enhanced in Álvarez et al. (2007), assuming that: the fluid is incompressible, its pressure is constant along the collector field, the thermal resistance of the pipe can be neglected and the temperature of the pipe does not vary along space. Eq. (3) models the collector plate dynamics and Eq. (4) describes the temperature of the fluid inside the collector ${ }^{2}$.

$$
\begin{aligned}
\rho_{m} C_{m} A_{p, e x t} \frac{d T_{p}}{d t}(t) & =d_{e} \pi \eta I(t) \\
& -d_{e} \pi h_{0}\left(T_{p}(t)-T_{e}(t)\right) \\
& -d_{i} \pi h_{i}\left(T_{p}(t)-T_{f}(t)\right), \\
\rho_{f} C_{f} A_{p, i n t} \frac{\partial T_{f}}{\partial t}(t, x) & =-\dot{q}_{c}(t) \rho_{f} C_{f} \frac{\partial T_{f}}{\partial x}(t, x) \\
& +d_{i} \pi h_{i}\left(T_{p}(t)-T_{f}(t)\right),
\end{aligned}
$$

wherein $I(t)$ is the amount of present solar irradiance (disturbance); $T_{p}$ and $T_{f}$ are, respectively, the collector plate and fluid temperatures; $\dot{q}_{c}$ is the inlet fluid; finally, $A_{p, e x t}$ and $A_{p, \text { int }}$ are, respectively, the external and internal surfaces of the absorber pipes, that have (internal, external) diameters of $d_{i}, d_{e}$.

Remark 1. All models have been Euler-discretized, with a sampling period of $T_{s}=3 \mathrm{~s}$, operational constraint of the CIESOL testbed.

\subsection{White-Box Least-Squares}

As the models of the water tanks and gas heater had already been accurately adjusted in previous works Pasamontes et al. (2013). Now, some identification results are presented in order to identify the parameters of the collector field model, given by Eqs. (3)-(4).

Remark 2. All model simulation and identification presented within this paper arise with the aid of tools Matlab and Yalmip toolbox. All identification procedures herein consider two SISO models: $i)$ from $\dot{q}_{c}(t)$ to $T_{f}(t)$; ii) from $I(t)$ to $T_{f}(t)$. To do so, $\dot{q}_{c}(t)$ is taken as a Pseudo-Random Binary Signal $(P R B S)$ and the effect of disturbances $\left(T_{e}\right.$, noise) is compensated (subtracted) from the measured outputs, considering the use of the adjusted models discussed above. The models that refer to the influence of the external temperature on $T_{f}(t)$ was not done because of the little effect that this variable has upon output $T_{f}(t)$.

A (white-box) Least-Squares method is performed, by solving the following Quadratic Problem $(Q P)$ :

$$
\min _{\rho} \frac{1}{N} \sum_{k=1}^{N}\left(y(k)-y_{m}(k)\right)^{2}
$$

where $y_{m}$ stands for the discretized version of (3)-(4) with the (known) inputs $\left(I, T_{e}, \dot{q}_{c}\right)$ and set of parameters $\rho$.

\footnotetext{
2 The collector plates are made out of a metal of density and heat transfer capacity constants $\rho_{m}, C_{m} . \eta$ is some thermal loss coefficient and $h_{0}$ and $h_{i}$ are heat transfer coefficients of the absorber and fluid.
} 
This procedure leads to the achieved parameters presented in Table 1 . These values are adequate, being sufficiently accurate in respect to Pasamontes et al. (2013).

Table 1. Identified Model Parameters

\begin{tabular}{|c|c|c|c|}
\hline$\rho_{m}$ & $1100 \mathrm{~kg} / \mathrm{m}^{3}$ & $C_{m}$ & $440 \mathrm{~J} /\left(\mathrm{kg}^{\circ} \mathrm{C}\right)$ \\
$A_{p, \text { ext }}$ & $0.0038 \mathrm{~m}^{2}$ & $A_{p, i n t}$ & $0.0013 \mathrm{~m}^{2}$ \\
$d_{i}$ & $0.04 \mathrm{~m}$ & $d_{e}$ & $0.07 \mathrm{~m}$ \\
$h_{0}$ & 11 & $h_{i}$ & 800 \\
$\rho_{f}$ & $1000 \mathrm{~kg} / \mathrm{m}^{3}$ & $C_{f}$ & $4018 \mathrm{~J} /\left(\mathrm{kg}^{\circ} \mathrm{C}\right)$ \\
\hline
\end{tabular}

\section{IDENTIFICATION-DERIVED MODELS}

This Section aims to achieve other models that describe the collector field dynamics, that are not phenomenological, but data-driven. This is interesting to be done once the phenomenological models given in Section 3 are quite complex, using partial differential equations do describe the system and a large number of parameters. The other models found arise from usual identification techniques, considering the available input/output data from used test-bench. Once again, remark that two SISO models are identified: $\dot{q}_{c} \rightarrow T_{f}$ and $I \rightarrow T_{f}$. Three different procedures are performed next. For further details refer to Ljung and Söderström (1983).

\subsection{Frequency-Wise Approach}

A simple frequency approach to model some systems is to, given its inputs $u$ and outputs $y$, achieve a dynamic description using the Fourrier transform $\mathcal{F}\{\cdot\}$, such as:

$$
H(j \omega)=\frac{\mathcal{F}\left\{\frac{d y}{d t}(t)\right\}}{\mathcal{F}\left\{\frac{d u}{d t}(t)\right\}},
$$

where $H(j \omega)$ is the response of the obtained model ${ }^{3}$. The time-response of the obtained model, then, can be retrieved using the convolution operator:

$$
\hat{y}(t)=\int_{-\infty}^{\infty} u(t-\tau) h(\tau) d \tau,
$$

where $h(t)$ is the inverse Fourrier transform of $H(j \omega)$.

\subsection{Extended Least-Squares}

Suppose the studied modern $S T$ system has an input/output relationship given by some $A R X$ model on the form:

$$
\begin{aligned}
y(k) & =a_{1} y(k-1)+\cdots+a_{n_{a}} y\left(k-n_{a}\right) \\
& +b_{1} u(k-1)+\cdots+b_{n_{b}} u\left(k-n_{b}\right)+e(k),
\end{aligned}
$$

with $n_{a}$ and $n_{b}$ being constant parametrical choices and $e(k)$ some colored noise. Then, to achieve an unpolarized estimation of these parameters $a_{1}, \ldots, b_{n_{b}}$, the following steps can be followed:

(i) Find a regression Equation with form $y(k)=\phi^{T}(k-$ 1) $\Theta+e(k)$

(ii) Determine the Least-Squares estimation $\hat{\Theta}$;

\footnotetext{
3 Previous low-pass filtering was realized in such way that highfrequency noise would not meddle the time-derivative computation.
}

(iii) Compute the residue vector $\epsilon=y-\phi \hat{\Theta}$ and use it as the initial guess for $e$ for the next iteration;

(iv) Iterate until convergence or some (normed) small residue is achieved.

\subsection{Nonlinear Least-Squares}

Another efficient identification tool, as proposed by Sjöberg et al. (1995), is the black-box nonlinear modelling framework, which considers that no prior knowledge of the system is available. The main idea of this procedure is to find a regression equation of form $y(k)=\mathcal{G}(\phi(k), \Theta)$, with $\mathcal{G}(\cdot)$ being some arbitrary nonlinear function. This work opts for a radial construction of this nonlinearity, that is $\mathcal{G}(\phi)=\kappa\left(\|\phi(k)-y(k)\|_{2}\right)$. This nonlinearity, herein, is taken as a polynomial dependence of inputs and outputs, perturbed by some colored noise $e$, such as:

$$
\begin{aligned}
& y(k)=\overbrace{\left[\begin{array}{lll}
a_{1}^{1} \ldots & a_{n_{a}}^{1}
\end{array}\right]}^{A^{1}} \overbrace{\left[\begin{array}{c}
y(k-1)^{1} \\
\vdots \\
y\left(k-n_{a}\right)^{1}
\end{array}\right]}^{\mathbf{Y}^{1}} \\
& +\cdots+A^{n_{y}} \mathbf{Y}^{n_{y}} \\
& +\overbrace{\left[\begin{array}{lll}
b_{1}^{1} \ldots & b_{n_{b}}^{1}
\end{array}\right]}^{B^{1}} \overbrace{\left[\begin{array}{c}
u(k-1)^{1} \\
\vdots \\
u\left(k-n_{b}\right)^{1}
\end{array}\right]}^{\mathbf{U}^{1}} \\
& +\cdots+B^{n_{u}} \mathbf{U}^{n_{u}}+e(k) \text {. }
\end{aligned}
$$

Then, the above parameters can be found by solving the $Q P$ below:

$$
\left\{A^{1}, \ldots, B^{n_{u}}\right\} \frac{1}{N} \sum_{k=1}^{N}\left(y(k)-y_{m}(k)\right)^{2}
$$

where $y_{m}$ refers to $(9)$ and $y$ the actual measurements.

\section{SOLAR IRRADIANCE PREDICTION}

This Section explains the used method to predict the future disturbances. For the case study, the estimated disturbances stand for the amount of solar irradiance present on field. The estimated curves are based upon real meteorological data from the state of Paraná, Brazil.

The used method is based on Nonlinear-Autoregressive $(N A R)$ Neural Networks with time delays (herein notated as $N N$ ). A successful example of the use of this kind of Neural Networks to predict time-series is seen in Zhang (2003). A time-series can be understood as a continuous or discrete sequence of events, and can be applied to identify and analyze the nature of different phenomena. It has to be clear, nonetheless, that the solar irradiance has a stochastic and, thus, some prediction error shall always exist: $\Delta q[k]=\hat{q}[k]-q[k]$.

The basic formulation of an artificial neural network is an artificial neuron. A set of synapses (input connections, $\left.x_{1} x_{2} \ldots x_{m}\right)$, weighted by individual weights $\left(w_{k_{1}} w_{k_{2}} \ldots w_{k_{m}}\right)$, is summed to a bias $b_{k}$ and produce and activity level $v_{k}$. This activity level is responsible for the 
activation (or not) of an activation function, $\phi(\cdot)$, which can lead to the presence of the output $y_{k}$. The topology of the neurones of the used NNs is presented in Figure 2.

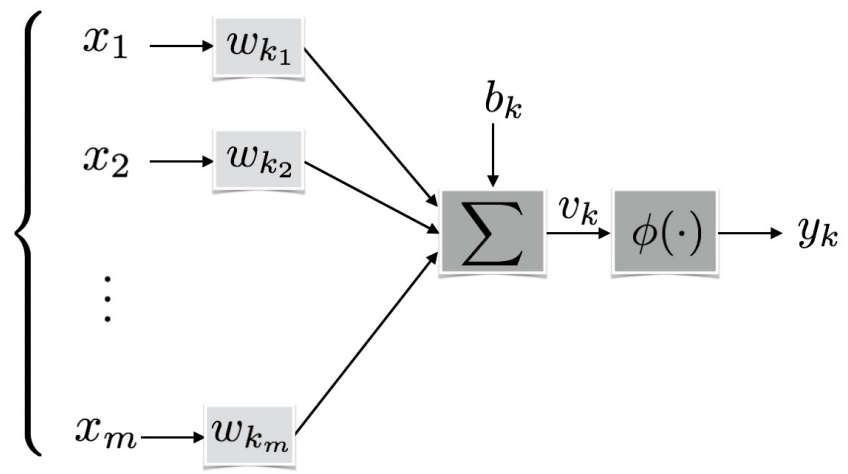

Figure 2. Artificial Neural Network

A validation step is necessary so that misplaced data is identified and corrected. With this step, the prediction model (given by each $N N$ ) does not learn based upon inconsistent data. It is also very important to state that two different predictions will be herein presented:

(1) one with $24 \mathrm{~h}$ ahead horizon, with $1 \mathrm{~h}$ samplings;

(2) and another for a half-month ahead horizon, with daily samplings.

The number of neurons and delay for each predictor are presented in Table 2, below. The computation and training algorithm for each Neural Network was done with the aid of a Levenberg-Marquardt optimization algorithm, that settles bias and weights for each $N N$.

Table 2. Topology of Used NNs

\begin{tabular}{c|c|c} 
Solar Irradiance. & $T_{s}=1 \mathrm{~h}$ & $T_{s}=24 \mathrm{~h}$ \\
\hline Layers & 1 & 1 \\
\hline Neurons & 1 & 5 \\
\hline Delay & 288 & 24 \\
\hline
\end{tabular}

The full-day-horizon predictions, updated every $T_{s}=1 \mathrm{~h}$, could serve, for instance, for an advanced control layer (such as an $M P C$ ) that aims to satisfy hourly demands of energy (and other constraints), as done in VergaraDietrich et al. (2017). Some estimation results using the described $N N$ technique are presented below. Figure 3 shows the prediction of solar irradiance for a full day interval, considering the daily predictions were done at midnight. Also, the real meteorological data is shown in this Figure, for comparison purposes.

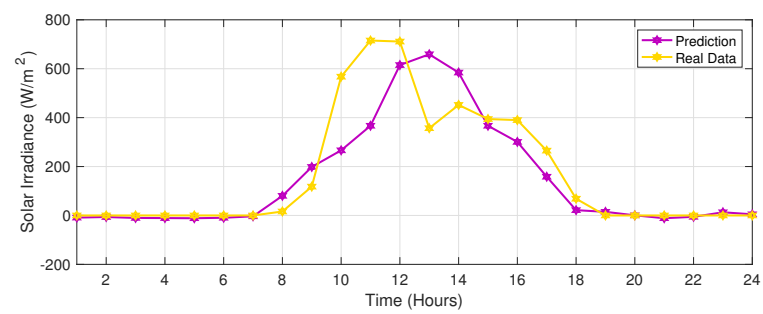

Figure 3. Hourly Solar Irradiance Prediction

Similarly, a 15-days-ahead predictor is also synthesized, but with daily iterations. This kind of predictor could serve for energy-planning control goals, as done in the works by Morato et al. (2017a). As explained, the information provided by the daily predictor is updated every $T_{s}=$ $24 \mathrm{~h}$. Unlike the daily predictor, this predictor provides an estimate of accumulated solar energy, per day, measured in $\frac{W}{m^{2}}$.

Figure 4 shows the prediction of profitable solar energy is shown for the horizon of 15 days. Once again, real data is also presented therein for comparison purposes.

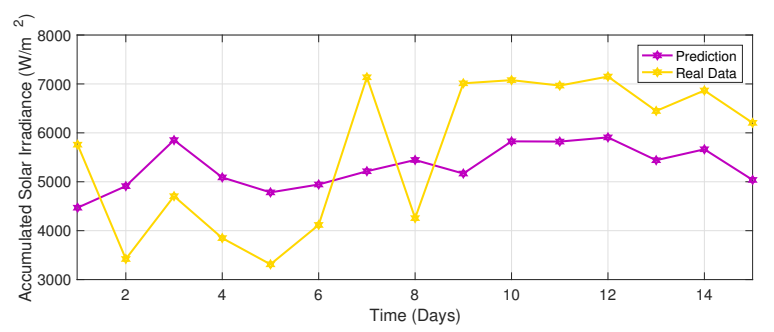

Figure 4. Daily Solar Irradiance Prediction

To summarize how accurate are the presented results, Table 3 elucidates the mean relative error of the predictions. This is computed as:

$$
M R E=\left(\frac{\sum_{k=0}^{N_{p}}\left(\|q[k]-\hat{q}[k]\|_{2}\right) / q[k]}{N_{p}}\right),
$$

where $q$ stands for the real solar irradiance data at instant $k$ and $\hat{q}$, the predictions. $N_{p}$ is the used horizon. Of course, the prediction error is not null, being sufficiently small to be used by some feedforward control technique.

Table 3. NN Solar Irradiance Results

\begin{tabular}{c|c|c} 
Horizon & Sampling Period & Solar Rad Irrad. \\
\hline $24 \mathrm{~h}$ & $1 \mathrm{~h}$ & $16.5 \%$ \\
15 days & $24 \mathrm{~h}$ & $20.6 \%$ \\
\hline
\end{tabular}

\section{RESULTS}

Validation results of the described models are presented in this Section. Using the considered softwares (see Remark 2), the obtained models of the solar collector are presented in Figure 5, wherein they are all simulated and compared to actual testbed data. Therein, PHM stands for the (adjusted) phenomenological models, $F R E Q$ for the frequency-wise identified models, $E L S$ for the extended least squares approach and POLY for the polynomial nonlinear least squares procedure. Via optimization, the best parametrical choices face to the minimization of modeldata residues were found, which gave: Model $\dot{q}_{c}(t) \rightarrow T_{f}(t)$ : for $E L S, n_{a}=n_{b}=2$, for POLY, $n_{a}=n_{b}=2, n_{y}=5$, $n_{u}=4$; Model $I(t) \rightarrow T_{f}(t)$ : for $E L S, n_{a}=n_{b}=1$, for POLY, $n_{a}=n_{b}=3, n_{y}=4, n_{u}=1$.

As evidenced by the results presented in Figure 5, the (adjusted) phenomenological models are very accurate, specially for the second dynamics $\left(I \rightarrow T_{f}\right)$. The identified POLY models also achieve very good performances, displaying consistent results.

Nonetheless, the ELS results have much less complexity (being linear, decoupled equations) and do present some sufficiently representative curves. This means that if there 


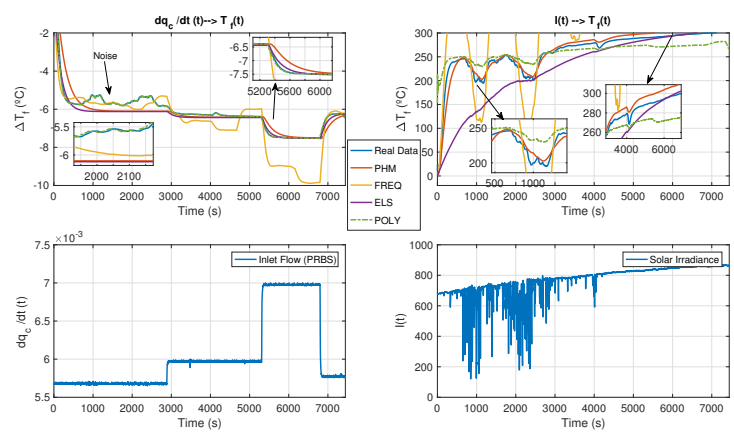

Figure 5. Final Achieved Results

is a need to control the modern $S T$ unit with advanced control techniques ( $M P C$, for instance), these models could be used in order to reduce the optimization complexity and simplify the control design issue. The FREQ models do follow the overall behaviour, but are much less realistic.

\section{CONCLUSIONS}

This work presented the issue of modelling modern solarheating facilities, that comprise solar collectors, accumulations tanks and an auxiliary gas heater. To do so, a phenomenological model is detailed, whose parameters are identified with a white-box least squares method. Another accurate model is derived from a black-box identification procedure. The two validated models could serve for both simulation and control design purposes. Complementary, a disturbance estimation layer is proposed to predict solar irradiance in different time horizons. With these two tools (accurate model and irradiance predictor), some optimal control scheme can be easily designed in such way that energy consumption is minimized and overall performance maximized. Future works include the application of model predictive control for such goals, with the aid of the developed tools, as suggested by the recent literature.

\section{REFERENCES}

Alarcon-Rodriguez, A., Ault, G., and Galloway, S. (2010). Multi-objective planning of distributed energy resources: A review of the state-of-the-art. Renewable and Sustainable Energy Reviews, 14(5), 1353-1366.

Álvarez, J., Yebra, L., and Berenguel, M. (2007). Repetitive control of tubular heat exchangers. Journal of Process Control, 17(9), 689-701.

Bujedo, L.A., Rodríguez, J., and Martínez, P.J. (2011). Experimental results of different control strategies in a solar air-conditioning system at part load. Solar energy, 85(7), 1302-1315.

Camacho, E.F., Berenguel, M., Rubio, F.R., and Martínez, D. (2012). Control issues in solar systems. In Control of Solar Energy Systems, 25-47. Springer.

Cruickshank, C.A. and Harrison, S.J. (2006). Experimental characterization of a natural convection heat exchanger for solar domestic hot water systems. In $A S M E$ 2006 International Solar Energy Conference, 425-431. American Society of Mechanical Engineers.

Dell, R. and Rand, D. (2001). Energy storage: a key technology for global energy sustainability. Journal of Power Sources, 100(1), 2-17.
Johansson, T.B. (1993). Renewable energy: sources for fuels and electricity. Island press.

Leblanc, J., Andrews, J., and Akbarzadeh, A. (2010). Low-temperature solar-thermal multi-effect evaporation desalination systems. International Journal of Energy Research, 34(5), 393-403.

Ljung, L. and Söderström, T. (1983). Theory and practice of recursive identification. MIT press.

Marc, O., Anies, G., Lucas, F., and Castaing-Lasvignottes, J. (2012). Assessing performance and controlling operating conditions of a solar driven absorption chiller using simplified numerical models. Solar Energy, 86(9), 22312239 .

Morato, M.M., Cani, A.A., Mendes, P.R., Normey-Rico, J.E., and Bordons, C. (2018). Future hybrid local energy generation paradigm for the brazilian sugarcane industry scenario. International Journal of Electrical Power and Energy Systems.

Morato, M.M., Mendes, P.R.C., Normey-Rico, J.E., and Bordons, C. (2017a). Advanced control for energy management of grid-connected hybrid power systems in the sugar cane industry. In Proceedings of the 20th IFAC World Congress. IFAC.

Morato, M.M., Mendes, P.R.C., Normey-Rico, J.E., and Bordons, C. (2017b). Optimal operation of hybrid power systems including renewable sources in the sugar cane industry. IET Renewable Power Generation, 11, 1237$1245(8)$.

Pasamontes, M., Álvarez, J., Guzman, J., Berenguel, M., and Camacho, E. (2013). Hybrid modeling of a solarthermal heating facility. Solar Energy, 97, 577-590.

Reikard, G. (2009). Predicting solar radiation at high resolutions: A comparison of time series forecasts. Solar Energy, 83(3), 342 - 349.

Rosiek, S. and Batlles, F. (2009). Integration of the solar thermal energy in the construction: Analysis of the solar-assisted air-conditioning system installed in ciesol building. Renewable Energy, 34(6), 1423-1431.

Shafiee, S. and Topal, E. (2009). When will fossil fuel reserves be diminished? Energy policy, 37(1), 181-189.

Shafiee, S. and Topal, E. (2010). A long-term view of worldwide fossil fuel prices. Applied Energy, 87(3), 9881000.

Sjöberg, J., Zhang, Q., Ljung, L., Benveniste, A., Delyon, B., Glorennec, P.Y., Hjalmarsson, H., and Juditsky, A. (1995). Nonlinear black-box modeling in system identification: a unified overview. Automatica, 31(12), 1691-1724.

Vergara-Dietrich, J.D., Morato, M.M., Mendes, P.R.C., Cani, A.A., Normey-Rico, J.E., and Bordons, C. (2017). Advanced chance-constrained predictive control for the efficient energy management of renewable power systems. Journal of Process Control.

Yu, Z., Jia, L., Murphy-Hoye, M.C., Pratt, A., and Tong, L. (2013). Modeling and stochastic control for home energy management. IEEE Transactions on Smart Grid, 4(4), 2244-2255.

Zhang, G.P. (2003). Time series forecasting using a hybrid arima and neural network model. Neurocomputing, 50, $159-175$. 